\title{
FILME JANELA DA ALMA REVISITADO - UMA CONVERSA COM O DIRETOR JOÃO JARDIM
}

\section{Dago Schelin *}

Há dois anos comecei meu doutorado na Philipps-Universitat Marburg aqui na Alemanha. Minha área é cinema, o tema mais específico é a visualidade. Há muitos filmes que tratam direta ou indiretamente de visão (e cegueira). Enquanto vou afunilando e delimitando o meu problema, deixo alguns filmes de lado e elejo outros para continuarem no corpus. Janela da Alma (2001), de João Jardim e Walter Carvalho é a cereja nesse bolo de filmes e está se tornando o principal para discutir dialéticas da visão. Há algum tempo eu queria conversar com João Jardim para tirar umas dúvidas, para trocar ideias e por simples curiosidade. Pensei que seria muito difícil conseguir um tempo com alguém que já esteve nomeado para um Oscar e ganhou prêmios na Berlinale e em Sundance. ${ }^{l}$ Mas para a minha grata surpresa João Jardim se dispôs de pronto a dar entrevista. Da entrevista deixei de fora somente os comentários iniciais de um fã lisonjeado. O texto abaixo tem a sensação de uma conversa pois foi exatamente isso.

\footnotetext{
* Doutorando. Philipps University Marburg, Institute for Media Studies (Institut für Medienwissenschaft), Programa de Doutoramento em Media Studies. 35039 Marburg, Alemanha. E-mail: dagols@gmail.com

1 Lixo Extraordinário (2011), dirigido por Lucy Walker, João Jardim e Karen Harley, ganhou o prêmio do público para o melhor documentário internacional no Festival de Sundance 2010, prêmios da Anistia Internacional e do público na mostra Panorama do Festival de Berlim 2010, indicado ao Oscar 2011 para o prêmio de melhor documentário.
} 
Entrevista realizada a 10 de agosto de 2015 via skype.

\section{Legenda:}

$\ldots \rightarrow$ micropausa ou interrupção ou alongamento vocálico.

$($...) $\rightarrow$ demonstração de corte em trechos não relevantes.

$(($ palavra $)) \rightarrow$ comentários da transcrição ou onomatopeias.

Dago Schelin: Mostrei Janela da Alma para um grupo de doutorandos e professores aqui em Marburg. Creio que seja porque o brasileiro tem um estereótipo tão forte que quem é de fora não espera, por exemplo, um filme que nem Janela da Alma vir de um brasileiro.

João Jardim: Totalmente. Inclusive quando o filme foi lançado aí, na verdade na França, eu senti que há uma resistência... eu lembro que teve um pouco esse preconceito. Eu li as críticas que saíram. Tinha um lado assim: "Mas por que um brasileiro fazer um filme sobre o pensamento, com tanta coisa mais interessante para ele falar do Brasil?" Era como se aquilo fosse um assunto que cabia mais a um europeu do que a um brasileiro. É como um francês fazer um filme sobre samba. E você, antes de ver se o filme é bom ou ruim,

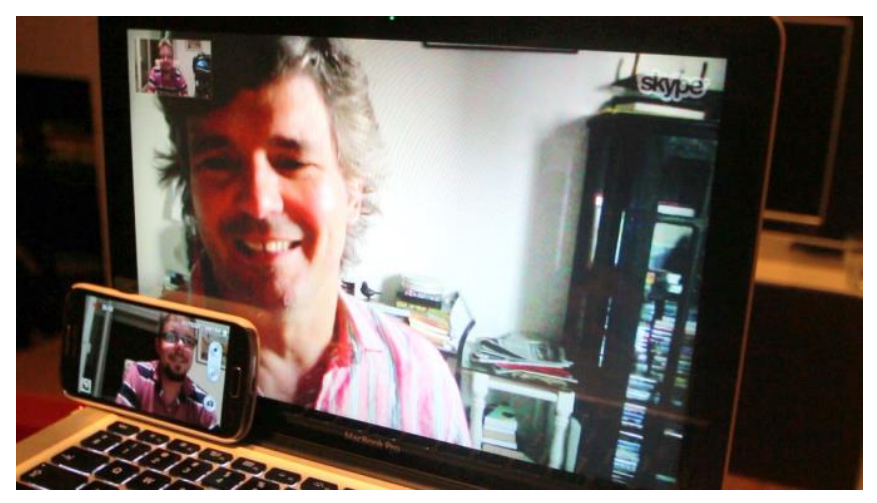
já vai dizer, "esse cara não tem autoridade para fazer um filme sobre isso". Em um primeiro momento eu até fiquei um pouco chateado, mas depois eu entendi que era natural, porque realmente tem uma estranheza mesmo. 
DS: De qualquer maneira, o pessoal pra quem eu mostrei aqui gostou muito do Janela da Alma. Fizeram-me várias perguntas que não pude responder. Uma pergunta sobre a ideia inicial: qual foi a primeira faísca que levou você a querer fazer um filme sobre esse tema?

JJ: Eu sempre fui muito míope, agora eu operei os olhos. Eu tive catarata e operei os olhos, mas eu era bastante míope, e aí eu comecei a ideia do filme, no caso, porque eu queria investigar como o fato de eu ser míope tinha influenciado a minha vida. Isso foi o primeiro momento (...) da minha insegurança, porque eu me sentia mais inseguro por causa disso. Isso foi uma primeira faísca. Depois essa ideia inicial até parece meio boba mas sem ela você não teria elaborado o todo. Mas eu me lembro bem que eu estava fazendo um trabalho nos Estados Unidos, eu morava no Brasil, mas eu fazia efeitos especiais comerciais em Nova Iorque. Eu me lembro que fui passar alguns dias lá fazendo esse comercial e saía com os olhos muito cansados de ficar vendo. Aí, pegava um táxi e tinha que andar várias ruas, tipo, setenta ruas entre o estúdio de pós-produção e o hotel. E eu tirava os óculos. E aí, aquela paisagem que é o que está no filme, aquela paisagem da cidade toda desfocada, (...) como ficava mais bonito o fora de foco do que o em foco, como a cidade ganhava toda uma magia da maneira, teoricamente, incorreta. Então, juntando essas duas questões, a minha questão da minha miopia, de como aquilo tinha afetado a minha personalidade e a ideia de que ver “errado", às vezes, pode ser ver melhor, essas duas ideias foram um ponto de partida do filme. Aí, eu comecei a pesquisar, conversar com pessoas, fui vendo que a questão do ver ou não ver, do ponto de vista pessoal, era muito mais interessante do que só as questões que eu estava levantando ali.

DS: No e-mail você me falou que pesquisou sobre o assunto visão. Como é que é isso para você?

JJ: Você começa a conversar com as pessoas. Eu chamei pessoas para trabalhar comigo em uma ideia, uma pesquisadora basicamente. Aí, você 
começa a conversar com pessoas de várias áreas da filosofia, da psicologia, da antropologia, da medicina, para tentar entender como é que funciona a visão em todos os sentidos. Os filósofos sempre falaram do ver. Você tem isso na medicina, você tem na arte, também. Só que eu notei que desse jeito não daria um filme, que era uma coisa muito técnica. Aquilo foi muito bom porque foi fazendo com que eu fosse cada vez procurando mais a subjetividade do tema, porque eu acho que o cinema passa muito por isso, pela questão subjetiva. $\mathrm{O}$ tema era muito subjetivo, por experiência própria e pelo que eu podia ler. A imagem é sempre muito mais aquilo que ela está te dizendo sem mostrar, que a essência da subjetividade é aquilo que está sendo dito e percebido sem estar sendo visto. Isso é a essência até do cinema e de todas as artes. Enfim, a arte funciona em um quadro, ele é emocionante justamente por causa disso, que não está no rabisco, o conjunto de tudo aquilo toca a gente de uma forma inexplicável, por isso aquilo funciona como arte. Foi a procura desse entendimento, do que é que significa isso (...) foi porque o filme todo foi feito. Eu fui pegando pessoas que podiam falar sobre isso. Quanto mais eu ia nessa direção, mais eu via que precisavam ser pessoas mais importantes, do ponto de vista do pensamento delas, (...) misturá-las com outras, vamos dizer assim, e aí, a gente fez cinquenta entrevistas para usar dezenove no filme.

DS: Isso é um dado bem interessante de vocês terem cinquenta entrevistas gravadas, mas na edição final entrarem só dezenove. É isso?

JJ: Isso. Exatamente.

DS: Quais são os critérios para descartar ou deixar uma entrevista, para você?

JJ: A palavra não seria exatamente "critério". Quando você vai para a ilha de edição, você já está construindo um filme. Você tem que obedecer a uma dramaturgia interna dele. Você não está mais fazendo um livro. Você está 
construindo um filme que tem que ter início, meio e fim, que tem que ter uma emoção. Cinema é uma coisa muito mais sensorial do que só informação, do que só reflexão. Essa é a diferença entre um filme ser chato ou não ser chato, que é aquilo que o filme está fazendo você pensar, ou está te provocando ali, para onde ele está te levando, para onde ele está levando a sua mente, que essa é a interatividade que existe, que é a real interatividade, que é aquilo que o filme está fazendo você pensar e sentir. A edição é uma parte disso porque quando você junta uma coisa na outra você já provoca um outro sentimento, que é a essência do cinema. Você bota uma imagem de um prato de comida e uma imagem de uma pessoa olhando (...) você assimila "ah, o cara está com fome." Essa mecânica é a força que move aquele processo. A única força é essa, é como que a junção de pensamentos que aquilo está provocando. Uma coisa quase química mesmo: juntar 'A' com 'B' vira 'C', não vira 'A+B'. Se você não cria esse sentimento, não cria o ser, você faz um filme que é ruim. Você tem 'A' mais 'B' mais 'C' mais 'D', mas o que torna interessante o Janela da Alma e os bons filmes, é que porque você junta uma ideia na outra, surge uma outra coisa. O que torna muitos filmes muito óbvios e muito comerciais é que eles são muito fáceis. Eles só vão até ali, enfim, levando você para um caminho que você já conhece.

DS: Eu acho que essa é uma característica que pelo menos os cinéfilos e os estudiosos de cinema gostam bastante em Janela da Alma, porque ele não é óbvio, justamente como você falou, é bem subjetivo. Para mim, pessoalmente, não tem um personagem que eu não goste de ouvir nesse filme. O começo com o Hermeto Pascoal, aliás, essa é uma pergunta que eu queria fazer: tem uma pessoa que fala com ele no início para ele olhar mais para a lente, para ele poder tirar o foco...

JJ: É o Walter Carvalho. 
DS: É o Walter Carvalho? Como é que foi essa interação com o Walter Carvalho antes de apertar o rec?

JJ: Esse foi o meu primeiro filme e eu, na verdade, me sentia pouco preparado para fazer um filme sozinho. Uma temática tão visual e tão... Eu achava que eu tinha que ter junto uma pessoa que tivesse mais vivência naquele tema. O Walter foi ótimo porque ele é um codiretor e ele deixou espaço para eu trabalhar, colocar no filme aquilo que eu acreditava que era o caminho e ao mesmo tempo me aconselhava "não, talvez isso não" e sugeria coisas, mas sempre de maneira muito generosa e nunca se apegando com nada. Ele sabia que o trabalho mais importante ali era que o filme estava nascendo de mim, foi indo até o final. Eu fiz a montagem toda sozinho. O Walter foi generoso o suficiente de entender isso. Mas eu diria que o filme não seria o que é sem ele, parceiro, generoso, indicando caminhos, dizendo o que poderia ser, o que não poderia ser, um ponto de saber. Algumas vezes aquilo não era seguido e aí, quando não era seguido, também estava tudo bem. A própria ideia do Hermeto Pascoal foi dele. Uma pessoa que foi uma (...) parceria maravilhosa, sabe, muito boa.

DS: O filme começa logo depois de umas imagens de um fogo, daí começa essa sequência com Hermeto Pascoal. Dá para perceber que tinha gente por trás, que tinha toda a preparação acontecendo de ajustar foco e preparar o entrevistado. Já estava valendo aquele momento?

JJ: Na verdade, a gente sabe que o filme está valendo o tempo todo, o filme vale o tempo todo. A gente está o tempo todo muito atento a tudo. O melhor que às vezes você pode conseguir de uma pessoa é justamente na hora que ela acha que não está valendo. Então, esse sentimento é proposital, para relaxar. O tempo todo você está muito ligado naquilo procurando o inusitado. 
DS: Qual que é o nível de preparação e o de "vamos ver o que é que vai acontecer" para você?

JJ: Tem que ter muita preparação. Você tem que chegar para conversar com essas pessoas muito bem preparado. Você tem pouco tempo com as pessoas. Elas têm mais o que fazer do que te dar entrevista. Mas, ao mesmo tempo, também tem que dar um espaço ali para coisas acontecerem. Você tem que fazer as duas coisas, você tem que estar muito preparado, mas estar muito atento. Se ela indicar um caminho melhor do que pelo qual você se preparou, você joga a sua preparação no lixo e segue. Eu acho que isso é fundamental em um trabalho de um documentarista: se prepara sabendo que pode jogar tudo fora, sabendo que pode vir uma outra coisa totalmente diferente. A gente tinha uma lista de assuntos que queria abordar e a gente ia conversando com as pessoas sobre aquelas coisas, e aí, a gente ia elencando um número de cada pessoa, o que é que cada pessoa podia falar sobre aqueles diferentes temas. Por isso alguns dos temas que o filme aborda não pediriam uma pessoa famosa para falar e então variava. Outras pessoas que até tinham uma reflexão. Mas apesar de terem uma história interessante para contar, não comunicavam aquela história de uma maneira cativante, interessante, e aí acabava que perdia força quando o filme ia para elas. Aí, elas foram sendo expulsas do filme, (...) pelo próprio filme, não por mim. Por isso é que foram feitas entrevistas, a gente elencou vários temas (...) só que aí, dava um desnível muito grande entre quem se expressava com clareza e emoção e quem se expressava com pouca clareza e pouca emoção. Essa é uma característica das pessoas. Não à toa elas são figuras representativas, têm uma representatividade no mundo de hoje, porque elas expressam suas ideias de maneira muito interessante. A câmera gosta disso, o filme gosta disso. Essas pessoas têm uma reflexão também. A Agnès Varda, a princípio, a gente não pensou em entrevistar. Mas a produtora pensou nela para alguma ponta, e aí, mandou uma mensagem para ela, lá na 
França, se ela teria alguma coisa para falar sobre esses temas, se em algum momento ela viu as coisas de maneira diferente, que a gente estava fazendo um filme sobre a visão e tal. E ela, na mesma hora, respondeu "sim, é um tema que me interessa, porque quando meu marido estava doente eu tive uma experiência...". Assim, ela falou de um filme que ela tinha feito, e aí, a gente "pô, imagina", na mesma hora, "vamos". O que ela estava dizendo ali, o que ela tinha para falar, não tinha nada a ver com o que a gente estava imaginando para o filme, mas você percebe que a pessoa reflete e pensa sobre aquele tema. Isso é mais importante do que o que eu estou imaginando. Não à toa foi maravilhosa a entrevista dela.

DS: Alguns dos entrevistados são cegos. Como é que é para você fazer um filme, que é uma arte audiovisual, com pessoas cegas e sobre cegueira? Essa questão passou pela sua cabeça?

JJ: Não, isso nunca foi uma questão porque a gente estava justamente entrevistando pessoas cegas que tinham uma visão de mundo interessante, e a gente percebeu muito rapidamente que o filme era sobre o discurso mais do que sobre a imagem. Mais importante do que aquilo que você vê é como você pensa sobre aquilo que você vê.

DS: Agora que Janela da Alma já está na adolescência, desde o lançamento em 2001, como é que você vê esse filme agora? Também agora que você já fez vários outros longas e ainda mais depois do sucesso de Lixo Extraordinário, enfim, você já tem uma bagagem.

JJ: Eu tenho muitas saudades do filme. O primeiro filme é uma coisa muito mágica porque a gente se dá a liberdade de descobrir como é que faz. Você não tem resposta nenhuma, só perguntas, então, isso te dá muita liberdade. Eu tenho muitas saudades. Depois que você faz o primeiro vem a convivência com o meio do documentário, com as pessoas que fazem documentário, os parceiros, os outros diretores, você já é muito influenciado 
pelo meio, pelo pensamento, e aquilo de alguma maneira te tira um pouco. Não é que tira, mas aquilo de alguma maneira acaba virando uma parede e você acaba tendo que andar dentro de algum trilho. Antes você não tinha trilho nenhum. Você ia, você tinha a liberdade de ir para onde você queria. A liberdade própria mesmo sua. Agora você já se sente mais na obrigação de otimizar o recurso, otimizar o tempo. Tem a questão do tempo também, que naquela época eu tinha todo o tempo do mundo. Então, eu olho para ele com muitas saudades daquele momento em que para mim era legítimo fazer qualquer ousadia. Hoje em dia, aqueles parâmetros nos quais você tenta se colocar são, com certeza, danosos. Mas é inevitável porque na verdade é o seu conhecimento. Não tem como você fingir que não tem aquele conhecimento. Mas aquele conhecimento que é também aquilo que te coloca em uma trilha pode te levar ainda mais longe. Você pode refletir melhor sobre as coisas e produzir obras até mais contundentes. Aquilo também é uma coisa que te cerceia. Então, como equilibrar isso? Eu acho que o Janela da Alma é fruto muito disso, de uma pessoa ou de duas pessoas, ou de muitas pessoas, que estavam ali tateando com muita liberdade um tema que é muito relevante. E aí, eu sinto falta dessa liberdade, enfim, mas não tem muito jeito. ((acha graça))

DS: Sobre as imagens de close-up, de pele humana, você pode falar um pouco disso?

JJ: A Agnès Varda falou disso e eu acho que tem uma relação com uma coisa que todo mundo que você vê, o tempo todo, mas você vê muito pouco como ela é imperfeita. A pele humana é muito imperfeita. O nosso olho é feito, como José Saramago fala, para perceber a pele humana de uma maneira. Ele consegue ver o detalhe o suficiente para você ver a pele humana de uma maneira bonita, por isso até que a pessoa quando fica velha, é menos interessante, ((acha graça)) porque ela começa a ter defeitos demais na pele. Então, eu acho que essa questão da capacidade que a gente tem de 
ver está justamente ligada intrinsicamente à nossa capacidade de perceber a quantidade de defeitos que têm na pele humana. Eu acho que é uma coisa muito forte, quando se vai perto da pele e você vê do que ela é feita. É disso que o filme tenta falar, como é que a gente não vê, e ao mesmo tempo está vendo tudo o que tem que ver.

DS: João, você teria mais alguma coisa para falar sobre Janela da Alma?

JJ: Eu acho o Janela da Alma um mergulho muito sincero, (...) dentro de um processo de criação. Por isso é que ele resultou de uma maneira tão interessante, porque ele é um mergulho muito profundo dentro de um assunto muito relevante. Quando as pessoas percebiam o quanto eu estava envolvido e mergulhado naquilo, elas entendiam, elas intuíam que o que elas dissessem para mim de relevante sobre aquele tema seria bem usado. Que aquilo para mim era muito relevante. E aí, houve essa troca. Elas doaram para mim, de maneira muito generosa, a vivência delas, o conhecimento delas sobre aquele tema. Eu fiquei ali na ilha de edição meses... e meses... e meses. Foram muitos meses de edição, tentando fazer, honrar, da melhor maneira possível, aquilo que tinha sido dito para mim, e eu acho que a gente fez um trabalho bom. Até gostaria que o filme fosse um pouco mais longo. Hoje em dia eu queria que ele tivesse uns - sei lá - cinco, oito minutos a mais, que (...) coisas incríveis que as pessoas falaram, que na hora eu acabei não usando. Mas, é um filme que trouxe muita satisfação, muito prazer e até hoje eu tenho muitas saudades dele, da época de fazê-lo. Uma saudade boa, não uma saudade nostálgica, mas uma coisa assim "nossa... como aquilo foi vivo". Mas, também (...) com certeza, foi um processo muito sofrido, porque eu não sabia direito o que eu estava fazendo, então, era muita persistência, insistência até fazer alguma coisa surgir.

DS: Dá para ver no filme. Dá para notar essas coisas boas. 
Dago Schelin

Daqui em diante ainda foram mais uns dois minutos de conversa para se despedir. Enquanto transcrevo esta entrevista, fico sabendo que faleceu Oliver Sacks, um dos entrevistados por João Jardim em Janela da Alma. No filme, Sacks fala sobre o olho da mente e chama este olhar de imaginação. Desde o lançamento do filme também já faleceu José Saramago em 2010. Dentre outras falas, Saramago comenta que "se Romeo tivesse os olhos de um falcão provavelmente não se apaixonaria por Julieta.”

Agora pretendo assistir Janela da Alma novamente para ver se vejo o filme com novos olhos, olhos imbuídos das lentes elucidativas do próprio cineasta. 